\title{
C-reactive protein elevation ratio as an early predictor of postoperative severe complications after laparoscopic gastrectomy for gastric cancer: a retrospective study
}

\author{
Hiroaki Tanaka* (1D, Tatsuro Tamura, Takahiro Toyokawa, Kazuya Muguruma, Naoshi Kubo, Katsunobu Sakurai and \\ Masaichi Ohira
}

\begin{abstract}
Background: In gastrectomy, postoperative elevation of C-reactive protein (CRP) is thought to be useful for predicting complications. Laparoscopic gastrectomy $(\mathrm{LG})$ is less invasive than laparotomy and the elevation of CRP is also mild. Postoperative complications such as anastomotic leakage not only increase the severity of the condition, but also carry a poor prognosis when treatment is delayed. Early treatment is therefore necessary.

Method: This retrospective study examined the relationship between occurrence of complications and the ratio of CRP levels on postoperative days 1 and 3 (CRP ratio) for 449 gastric cancer patients who underwent LG in the Department of Gastrointestinal Surgery at Osaka City University Hospital between 2006 and 2016.
\end{abstract}

Results: We observed that factors associated with postoperative complications were preoperative renal failure and CRP ratio. No significant associations with surgical procedure, operation time, bleeding volume, age, obesity, measured CRP concentration, or white blood cell count were evident. The optimal cut-off for CRP ratio to predict postoperative complications from the receiver operating characteristic curve was 2.13.

Conclusion: Our results suggested that the risk of severe postoperative complications after LG could be predicted using the CRP ratio.

Keywords: Laparoscopic gastrectomy, Postoperative complication, C-reactive protein, Gastric cancer

\section{Introduction}

Laparoscopic gastrectomy (LG) is widely accepted in East Asia as a minimally invasive surgery for gastric cancer [1]. The benefits of LG include reduced surgical trauma, pain and quick recovery [2, 3]. Postoperative complications, however, still occur even after LG, and the overall postoperative complication rate after gastrectomy has been reported as 7-28\% [4-6]. Surgeons should recognize the risk of complications before the presentation of overt symptoms and seek early diagnosis, because complications after gastrectomy may adversely

\footnotetext{
* Correspondence: hiroakitan@med.osaka-cu.ac.jp

Department of Gastroenterological Surgery, Osaka City University Graduate School of Medicine, 1-4-3 Asahi-machi, Abeno-ku, Osaka 545-8585, Japan
}

affect long- and short-term outcomes in patients [7-9]. With regard to gastrectomy, several investigators have reported a relationship between postoperative C-reactive protein elevation and complications [10-13]. However, those reports analyzed values from datasets that included open gastrectomy (OG). Suitable CRP-related values to predict postoperative complications after LG thus remain uncertain. We hypothesized that postoperatively elevated CRP concentrations would be predictive of postoperative complications after LG.

The aim of this retrospective study was to investigate the elevation rate of CRP as an early predictor of postoperative complications after LG for gastric cancer.

(c) The Author(s). 2019 Open Access This article is distributed under the terms of the Creative Commons Attribution 4.0 International License (http://creativecommons.org/licenses/by/4.0/), which permits unrestricted use, distribution, and 


\section{Patients and methods}

\section{Patients and data collection}

Data were obtained from 449 patients with histologically confirmed gastric cancer who had undergone LG with lymph node dissection between 2006 and 2016 in the Department of Surgical Oncology at Osaka City University. Stage and other information including macroscopic type, histology, depth of tumor (T), lymph node metastasis $(\mathrm{N})$, distant metastasis $(\mathrm{M})$, lavage cytology $(\mathrm{CY})$, and lymphatic or venous involvement were classified according to the criteria of the 3rd edition of Japanese Classification of Gastric Carcinoma by the Japanese Gastric Cancer Association. Data for clinicopathological characteristics, intra-operative findings, and postoperative course were extracted from our database. The Clavien-Dindo (CD) classification was adopted for evaluating postoperative complications [14]. Complications were defined as those of CD grade II or higher, with complications of grade IIIa or higher considered severe. This retrospective study was approved by the ethics committee of Osaka City University (\#4038) and carried out according to the Declaration of Helsinki. We collected laboratory data including white blood cell count (WBC), neutrophil count, lymphocyte count, and CRP concentration on postoperative days (POD) 1 and POD3. The CRP ratio was defined as: (CRP concentration on POD3) / (CRP concentration on POD1).

\section{Statistical analysis}

Relationships between complications and other variables were analyzed using the Mann-Whitney U test. Uni- and multivariate logistic regression analyses were performed. Values of $P<0.05$ were considered statistically significant. The cut-off value for the CRP ratio was determined using receiver operating characteristic (ROC) curves. Analysis was performed using $\mathrm{JMP}^{\circledR}$ version 11 software (SAS Institute, Cary, NC). The area under the curve and 95\% confidence interval of the ROC curve and the power of this study were calculated using EZR (Saitama Medical Center, Jichi Medical University, Saitama, Japan), a graphical user interface for $\mathrm{R}$ (The $\mathrm{R}$ Foundation for Statistical Computing, Vienna, Austria). More precisely, EZR is a modified version of $\mathrm{R}$ Commander designed to add statistical functions frequently used in biostatistics [15].

\section{Results}

\section{Patient characteristics}

Background characteristics of the cohort in this study are summarized in Table 1 . Of the 449 patients, 41 (9.1\%) were more than 80 years old, and 57 (12.6\%) had a body mass index $>25 \mathrm{~kg} / \mathrm{m}^{2}$. Some form of comorbidity was identified in 77 patients (17.1\%), including diabetes mellitus, renal dysfunction, ischemic heart disease, brain infarction, liver cirrhosis, and chronic obstructive pulmonary disease. Twenty patients showed multiple comorbidities. Distal gastrectomy was performed for 393 patients (87.5\%), and D2 lymph node dissection for 48 patients (10.6\%). Mean intraoperative blood loss was $121 \mathrm{~g}$ and mean operation time was 283 min. Pathological results were stage I in 389 (86.6\%) patients, stage II in 41 (9.3\%), and stage III in $19(4.2 \%)$. Median white blood cell count was $10,000 / \mathrm{mm}^{3}$ on POD1 and $7000 / \mathrm{mm}^{3}$ on POD3, and median CRP concentration was $5.8 \mathrm{mg} / \mathrm{dL}$ on POD1 and $7.3 \mathrm{mg} / \mathrm{dL}$ on POD3.

\section{Association of postoperative complications with perioperative background}

Postoperative complications are summarized in Table 2. Minor complications (less than CD grade II) included wound site infection, elevated CRP, fever, and intestinal paralysis. Most instances of infectious complications, such as anastomotic leakage and pancreatic fistula, were CD grade III or more. Severe complications (CD grade III or more) occurred in 33 patients $(7.3 \%)$ (17 cases of anastomotic leakage, 6 cases of pancreatic fistula, 4 cases of intraabdominal abscess, 2 cases of aspiration pneumonia, and 2 cases of strangulation ileus). Three patients showed multiple complications of anastomotic leakage and pancreatic fistula. One patient with CD Grade 5 complications died of cardiac infarction.

We observed no associations of gender, age, or obesity with postoperative complications (Table 1). Complication rates were high in patients with diabetes, patients with renal dysfunction requiring artificial dialysis, and patients with multiple comorbidities, ranging from 15 to $52 \%$. We found no statistical differences in complication rates between patients after laparoscopic total gastrectomy (LTG) and laparoscopic distal gastrectomy (LDG). Anastomotic leakage was observed in 8 cases of LTG and 10 cases of LDG. Although the amount of intraoperative blood loss, operation time, and lymph node dissection showed no correlations, complications occurred frequently in cases where the pathological TNM stage was II/III.

\section{Impact of postoperative laboratory data on complications and predictive value of CRP ratio}

No factors in postoperative blood data showed associations with complications, including CRP, white blood cells, and neutrophils, which were considered as markers of bacterial infection. Since blood test data were obtained on POD1 and POD3, the difference and rate of change were calculated and correlations with complications were investigated. No association was identified between changes in WBC, CRP, or neutrophil count, but an association was identified between the CRP ratio and complications (Table 1). Multivariate analysis identified 
Table 1 Patients characteristics and difference between severe complitcation and no or mild complication

\begin{tabular}{|c|c|c|c|c|}
\hline & Total patients $(n=449)$ & Severe Complication $(n=33)$ & No or mild complication $(n=416)$ & $p$ value \\
\hline \multicolumn{5}{|l|}{ Age } \\
\hline$\leq 80$ & 408 & 29 & 379 & \multirow[t]{2}{*}{0.535} \\
\hline$\leq 81$ & 41 & 4 & 37 & \\
\hline \multicolumn{5}{|l|}{ Sex } \\
\hline Male & 299 & 27 & 272 & \multirow[t]{2}{*}{0.325} \\
\hline Female & 150 & 6 & 144 & \\
\hline \multicolumn{5}{|l|}{$\mathrm{BMI}$} \\
\hline$\leq 25$ & 392 & 27 & 365 & \multirow[t]{2}{*}{0.325} \\
\hline$>25$ & 57 & 6 & 51 & \\
\hline \multicolumn{5}{|l|}{ Preoperative comorbidity } \\
\hline DM & 62 & 10 & 52 & 0.004 \\
\hline Renal dysfuction & 5 & 3 & 2 & $<0.001$ \\
\hline Ischemic heart disease & 28 & 4 & 24 & 0.146 \\
\hline Brain infarction & 25 & 2 & 23 & 0.898 \\
\hline Liver cirrhosis & 5 & 0 & 5 & 0.526 \\
\hline COPD & 14 & 1 & 13 & 0.976 \\
\hline Multiple Comorbidities & 20 & 3 & 17 & 0.011 \\
\hline \multicolumn{5}{|l|}{ Operation time } \\
\hline Average (min) & 281 & 280 & 283 & 0.813 \\
\hline \multicolumn{5}{|l|}{ Blood loss } \\
\hline Average (g) & 121 & 124 & 121 & 0.936 \\
\hline \multicolumn{5}{|l|}{ Surgery } \\
\hline DG & 393 & 26 & 367 & \multirow[t]{2}{*}{0.145} \\
\hline TG & 56 & 7 & 49 & \\
\hline \multicolumn{5}{|l|}{ Lymphatic dissection } \\
\hline D1, D1+ & 401 & 32 & 369 & \multirow[t]{2}{*}{0.334} \\
\hline D2 & 48 & 1 & 47 & \\
\hline \multicolumn{5}{|l|}{ pathological T category } \\
\hline $\mathrm{pT} 1,2$ & 411 & 26 & 385 & \multirow[t]{2}{*}{0.012} \\
\hline $\mathrm{pT} 3,4$ & 38 & 7 & 31 & \\
\hline \multicolumn{5}{|l|}{ pathological $\mathrm{N}$ category } \\
\hline pNO & 385 & 25 & 360 & \multirow[t]{2}{*}{0.302} \\
\hline $\mathrm{pN1} 1,2,3$ & 64 & 8 & 56 & \\
\hline \multicolumn{5}{|l|}{ pathological Stage } \\
\hline Stage I & 389 & 25 & 364 & \multirow[t]{2}{*}{0.005} \\
\hline Stage $\|\| \|$, & 60 & 8 & 52 & \\
\hline \multicolumn{5}{|l|}{ Laboratory data } \\
\hline \multicolumn{5}{|l|}{ Day1 (Median) } \\
\hline WBC (×10/mm3) & 100 & 101 & 99 & 0.186 \\
\hline CRP $(\mathrm{mg} / \mathrm{dL})$ & 5.75 & 4.5 & 6.3 & 0.057 \\
\hline Neutrophils (\%) & 83.8 & 84.3 & 83.6 & 0.243 \\
\hline Lymphocyte (\%) & 10.5 & 10 & 11 & 0.954 \\
\hline \multicolumn{5}{|l|}{ Day3 (Median) } \\
\hline WBC $(\times 10 / \mathrm{mm} 3)$ & 70 & 85 & 68 & 0.373 \\
\hline
\end{tabular}


Table 1 Patients characteristics and difference between severe complitcation and no or mild complication (Continued)

\begin{tabular}{|c|c|c|c|c|}
\hline & Total patients $(n=449)$ & Severe Complication $(n=33)$ & No or mild complication $(n=416)$ & $p$ value \\
\hline CRP (mg/dL) & 7.3 & 13.5 & 6.3 & 0.671 \\
\hline Neutrophils (\%) & 79.4 & 78.7 & 49.1 & 0.501 \\
\hline Lymphocyte (\%) & 15 & 12.3 & 15.5 & 0.079 \\
\hline \multicolumn{5}{|l|}{ Difference (Day3-Day1) } \\
\hline DWBC (×10/mm3) & -28 & -19 & -32 & 0.483 \\
\hline DCRP & 1.39 & 9 & 0.4 & 0.113 \\
\hline Dneutrophils (×10/mm3) & -31 & -20 & -31 & 0.741 \\
\hline \multicolumn{5}{|l|}{ Ratio (Day3/Day1) } \\
\hline \multicolumn{5}{|l|}{ (Median) } \\
\hline WBC & 0.7 & 0.8 & 0.7 & 0.844 \\
\hline CRP & 1.28 & 2.9 & 1.1 & 0.003 \\
\hline Neutrophils & 0.6 & 0.7 & 0.58 & 0.768 \\
\hline
\end{tabular}

pathological stage, multiple comorbidities, and CRP ratio as independent predictors of severe postoperative complications (Table 3).

To determine the optimal cut-off for CRP ratio, we analyzed the ROC curve (Fig. 1a). A cut-off CRP ratio of 2.13 offered $55 \%$ sensitivity and $82 \%$ specificity for postoperative severe complication, representing the optimal cut-off. The area under curve (AUC) was as low as 0.592, but in comparison, the AUC for CRP on POD3 was 0.489 (Fig. 1b). We then divided patients into two groups: high CRP ratio $(\geq 2.1), 92$ patients (20\%); and low CRP ratio $(<2.1), 357$ patients $(80 \%)$ (Table 4$)$. Of the 357 patients, 339 showed no complications after surgery, indicating a negative predictive value of $94 \%$. On the other hand, the positive predictive value for postoperative complications was $16 \%$.

\section{Discussion}

This study showed a significant association between postoperative CRP elevation and severe postoperative complications after LG. Moreover, CRP ratio, defined

Table 2 Postoperative compications

\begin{tabular}{|c|c|c|c|c|c|c|c|c|}
\hline & No & Cla & ien- & Sind & clas & sificat & ion & \\
\hline & & I & $\|$ & IIla & $\mathrm{IIlb}$ & $\mathrm{IVa}$ & $\mathrm{IVb}$ & $\bar{V}$ \\
\hline total & 358 & 24 & 34 & 22 & 1 & 5 & 2 & 3 \\
\hline Anastomotic leakage & 0 & 0 & 1 & 11 & 1 & 2 & 2 & 1 \\
\hline Pancreatic fistula & 0 & 0 & 8 & 6 & 0 & 0 & 0 & 0 \\
\hline Intraabdominal abscess & 0 & 0 & 1 & 4 & 0 & 0 & 0 & 0 \\
\hline Aspiration Pneumonia & 0 & 0 & 0 & 1 & 0 & 1 & 0 & 1 \\
\hline Strangulation ileus & 0 & 0 & 0 & 0 & 0 & 2 & 0 & 0 \\
\hline Bleeding & 0 & 0 & 0 & 2 & 0 & 1 & 0 & 0 \\
\hline Other & 0 & 24 & 24 & 1 & 0 & 0 & 0 & 1 \\
\hline
\end{tabular}

here as the ratio of CRP levels on POD1 and POD3, represented an independent risk factor for severe postoperative complications.

LG offers various advantages over OG, including shorter duration of hospitalization, reduced blood loss, faster recovery of bowel movement, and earlier ambulation [16]. An updated meta-analysis found no significant difference in postoperative complication rates between LG and OG groups for advanced gastric cancer [17]. Postoperative complications reportedly occurred in 9.8$12.7 \%$ of LG patients with stage I or II cancer in two Asian studies $[17,18]$. We observed that the complication rate was $14.9 \%$ for CD grade II or more and $7.3 \%$ for CD grade III or more in the present study. Postoperative intra-abdominal infectious complications such as anastomotic leakage, pancreatic fistula, and intraperitoneal abscess increase surgical stress and cause severe tissue damage due to local and generalized inflammatory reactions, resulting in more severe immune suppression [9].

Numerous studies have identified postoperative CRP concentration as a risk factor for postoperative complications after gastrointestinal cancer surgery, including colorectal cancer, esophageal cancer, and gastric cancer [12, 19-21]. In minimally invasive surgery and laparotomy for colorectal and gastric cancer, postoperative CRP levels have been observed to be significantly lower after minimally invasive surgery if no complications arise [22-24]. Many previous reports on the association between CRP and postoperative infectious complications have involved a mixture of laparotomy and laparoscopic surgery. Of the few reports that have focused on laparoscopic surgery, 300 to 400 cases were examined, with LG accounting for less than $50 \%$ of those cases $[10,12,19]$. No marked difference was seen between CRP levels in those reports and levels in laparotomy cases only, and peak CRP concentration is usually observed on POD3 or 
Table 3 Multivariate analysis

\begin{tabular}{|c|c|c|c|c|c|}
\hline & Standard error & Wald-square & $p$ value & Odds ratio & $95 \% \mathrm{Cl}$ \\
\hline CRP ratio & 0.33 & 11.393 & 0.001 & 3.67 & $1.7300-7.860$ \\
\hline pStage & 0.386 & 8.195 & 0.004 & 5.6 & $1.710-18.400$ \\
\hline Multiple Comobidities & 0.852 & 10.63 & 0.004 & 3.27 & $1.470-7.280$ \\
\hline $\mathrm{R} 2=0.117 \mathrm{Pr}>$ ChiSq 0.0002 & Goodness-of-fit statistics Pr > ChiSq 0.343 & & & & \\
\hline
\end{tabular}

POD4, with a threshold for predicting complications of $12-17.7 \mathrm{mg} / \mathrm{dL}$ [11-13, 25]. Although fewer than 300 cases have previously been reported when limited to laparoscopic surgery, 440 cases were reported in the present study. The significance of this report is considered to be equivalent to that of other reports.

Elevated CRP as a predictor of postoperative complications has usually been examined at a single time point. In this study, however, CRP levels on POD3 alone were not associated with complications. One reason for this was likely to be the fact that we examined patients with serious complications other than infectious complications, such as cases requiring reoperation due to severe adhesive ileus, cases of shock due to postoperative bleeding, and cases of death due to myocardial infarction early after surgery. Moreover, high CRP levels were associated with long operation time, greater blood loss, and high BMI. We observed a CRP concentration $>17.5 \mathrm{mg} / \mathrm{dL}$ on POD3 in $10 \%$ of patients without complications. We therefore focused on the "CRP ratio" to predict postoperative complications. Another reason for using the CRP ratio in this study was the difficulty of setting cut-off values. CRP levels on POD3 were elevated to the same level in both LG and OG groups with and without complications after colorectal cancer surgery, and CRP levels on POD3 were not final predictors of complications [23]. Elevated CRP levels $\geq 10 \mathrm{mg} / \mathrm{dL}$ are generally considered clinically indicative of marked inflammation, but the wide range of cut-off values reported previously can make clinical application of such findings difficult [26]. We showed a negative predictive value of $94 \%$ for CRP ratio in this study. As the number of minimally invasive surgeries continues to increase, the length of hospital stays may be shortened. A recently published meta-analysis reported the importance of CRP level on POD3 in predicting readmission after radical gastrectomy [27]. Those results suggest that the CRP elevation rate after surgery may be useful for safely determining early discharge.

Several limitations to this study must be considered. This was a single-center, retrospective, observational study and the sample size was small. The power of this study was relatively low, at 0.78 , because of the small number of samples. This represents a substantial weakness in the statistical analysis. Validation studies using larger cohorts from multiple centers are needed to confirm the impact of CRP ratio on postoperative complications. Second, only short-term surgical outcomes were evaluated. Pancreatic fistula or intraperitoneal abscess appearing 2 weeks or more after surgery appear
A

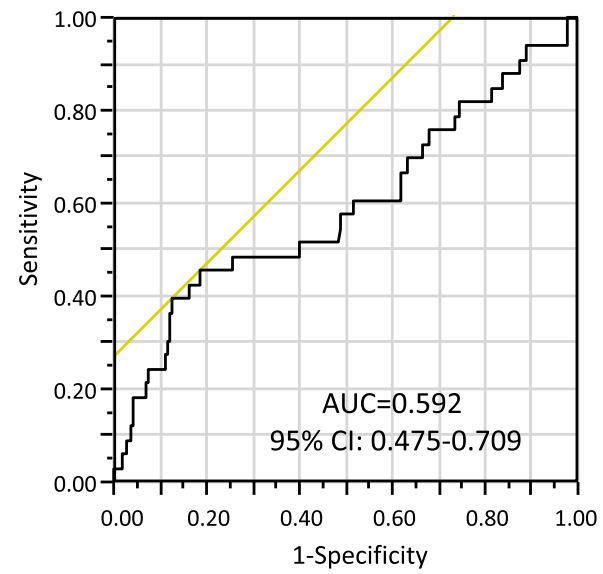

B

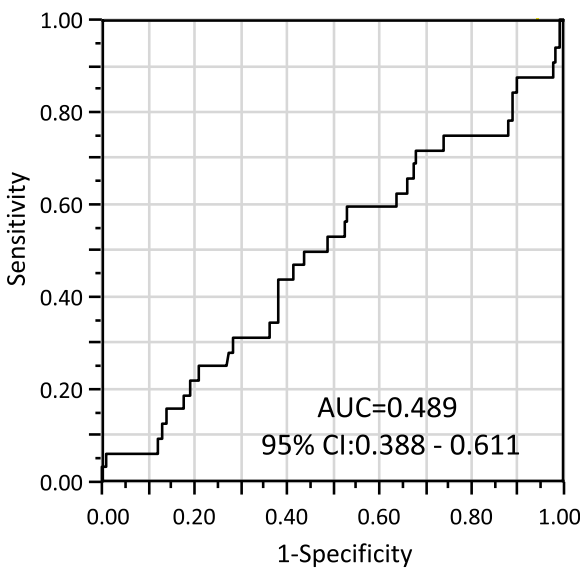

Fig. 1 Receiver operating characteristic (ROC) curves for CRP ratio and CRP on postoperative day 3. We used the continuous variable density of CRP ratio (a) and CRP on postoperative day $3(\mathbf{b})$ as the test variable and postoperative complications as the state variable. Area under ROC curve was 0.592 for CRP ratio and 0.498 for CRP on postoperative day 3. An investigation of cut-off scores showed the optimal cut-off for CRP ratio was 2.13 (sensitivity, 0.454 ; specificity, 0.815 ). We therefore set 2.13 as the cut-off for CRP ratio 
Table 4 Predicitive valuse according to CRP elevation ratio

\begin{tabular}{lcl}
\hline & \multicolumn{2}{l}{ CRP elevation ratio } \\
\cline { 2 - 3 } & $\geq 2.13(n=92)$ & $<2.13(n=357)$ \\
\hline Severe Complication & 15 & 18 \\
No or mild comprication & 77 & 339 \\
\hline
\end{tabular}

unlikely to be anticipated using data from POD3. Third, other parameters that were not assessed included the CRP-to-albumin ratio, estimated glomerular filtration rate, platelet-to-lymphocyte ratio, sarcopenia, and preoperative prealbumin concentration [28-32]. We observed that the complication rate was significantly higher in patients with renal failure on dialysis. Immune response, nutritional condition, and performance status should also be investigated. Despite these limitations, CRP ratio appears potentially useful as an easily understood value for clinical use.

\section{Conclusion}

In conclusion, our findings suggested that CRP ratio after laparoscopic gastrectomy could offer a useful predictor of postoperative complications likely to need treatment. Our results suggest that unnecessary treatments such as drain replacement and antibiotics might be obviated when the CRP ratio is low on POD3 after LG.

\section{Abbreviations \\ AUC: Area under curve; CD: Clavien-Dindo; CRP: C-reactive protein; LDG: Laparoscopic distal gastrectomy; LG: Laparoscopic gastrectomy; LTG: Laparoscopic total gastrectomy; OG: Open gastrectomy; POD: Postoperative day; ROC: Receiver operating characteristic}

\section{Acknowledgements}

Not applicable

\section{Authors' contributions}

$\mathrm{HT}$ and $\mathrm{MO}$ contributed to study conception and design and preparation of the manuscript. TT1 (Tatsuro Tamura) contributted data analysis and interpretation. TT2 (Takahiro Toyokawa), KM, NK and KS participated in data collection and analysis. All authors read and approved the final manuscript.

\section{Funding}

Not applicable

\section{Availability of data and materials}

The datasets used and/or analysed during the current study are available from the corresponding author on reasonable request.

\section{Ethics approval and consent to participate}

Our investigation was carried out according to the Declaration of Helsinki. All experimental procedures after 2013 were approved as No. 4038 by the Osaka City University ethics committee, and all patients had provided written informed consent for collection and analysis of the specimens. On the other hand, because the other experimental procedures up to 2013 were only allinclusive consent, we are showing opt-out form as an observational study.

\section{Consent for publication}

Not applicable

\section{Competing interests}

The authors declare that they have no competing interests.
Received: 30 April 2019 Accepted: 14 August 2019

Published online: 20 August 2019

\section{References}

1. Kitano S, Iso Y, Moriyama M, Sugimachi K. Laparoscopy-assisted Billroth I gastrectomy. Surg Laparosc Endosc. 1994;4(2):146-8.

2. Kim YW, Baik YH, Yun YH, Nam BH, Kim DH, Choi IJ, Bae JM. Improved quality of life outcomes after laparoscopy-assisted distal gastrectomy for early gastric cancer: results of a prospective randomized clinical trial. Ann Surg. 2008;248(5):721-7.

3. Lee JH, Han HS. A prospective randomized study comparing open vs laparoscopy-assisted distal gastrectomy in early gastric cancer: early results. Surg Endosc. 2005;19(2):168-73.

4. Tu RH, Lin JX, Zheng CH, Li P, Xie JW, Wang JB, Lu J, Chen QY, Cao LL, Lin $\mathrm{M}$, et al. Complications and failure to rescue following laparoscopic or open gastrectomy for gastric cancer: a propensity-matched analysis. Surg Endosc. 2017;31(5):2325-37.

5. Kim KM, An JY, Kim HI, Cheong JH, Hyung WJ, Noh SH. Major early complications following open, laparoscopic and robotic gastrectomy. $\mathrm{Br} J$ Surg. 2012;99(12):1681-7.

6. Kim W, Kim HH, Han SU, Kim MC, Hyung WJ, Ryu SW, Cho GS, Kim CY, Yang HK, Park DJ, et al. Decreased morbidity of laparoscopic distal gastrectomy compared with open distal gastrectomy for stage I gastric Cancer: shortterm outcomes from a multicenter randomized controlled trial (KLASS-01). Ann Surg. 2016;263(1):28-35.

7. Sierzega M, Kolodziejczyk P, Kulig J, Polish gastric Cancer study G. Impact of anastomotic leakage on long-term survival after total gastrectomy for carcinoma of the stomach. Br J Surg. 2010;97(7):1035-42.

8. Ito $Y$, Kanda M, Ito S, Mochizuki Y, Teramoto H, Ishigure K, Murai T, Asada T, Ishiyama A, Matsushita $\mathrm{H}$, et al. Intraoperative blood loss is associated with shortened postoperative survival of patients with stage II/III gastric Cancer: analysis of a multi-institutional dataset. World J Surg. 2019;43(3):870-7.

9. Tokunaga M, Tanizawa Y, Bando E, Kawamura T, Terashima M. Poor survival rate in patients with postoperative intra-abdominal infectious complications following curative gastrectomy for gastric cancer. Ann Surg Oncol. 2013; 20(5):1575-83.

10. Shishido Y, Fujitani K, Yamamoto K, Hirao M, Tsujinaka T, Sekimoto M. C-reactive protein on postoperative day 3 as a predictor of infectious complications following gastric cancer resection. Gastric Cancer. 2016; 19(1):293-301.

11. Matsunaga $T$, Saito $H$, Murakami $Y$, Kuroda $H$, Fukumoto $Y$, Osaki T. Serum level of C-reactive protein on postoperative day 3 is a predictive indicator of postoperative pancreatic fistula after laparoscopic gastrectomy for gastric cancer. Asian J Endosc Surg. 2017;10(4):382-7.

12. Kim EY, Yim HW, Park CH, Song KY. C-reactive protein can be an early predictor of postoperative complications after gastrectomy for gastric cancer. Surg Endosc. 2017;31(1):445-54.

13. Saito T, Kurokawa Y, Miyazaki Y, Makino T, Takahashi T, Yamasaki M, Nakajima K, Takiguchi S, Mori M, Doki Y. Which is a more reliable indicator of survival after gastric cancer surgery: postoperative complication occurrence or C-reactive protein elevation? J Surg Oncol. 2015;112(8):894-9.

14. Clavien PA, Barkun J, de Oliveira ML, Vauthey JN, Dindo D, Schulick RD, de Santibanes E, Pekolj J, Slankamenac K, Bassi C, et al. The Clavien-Dindo classification of surgical complications: five-year experience. Ann Surg. 2009; 250(2):187-96.

15. Kanda Y. Investigation of the freely available easy-to-use software 'EZR' for medical statistics. Bone Marrow Transplant. 2013;48(3):452-8.

16. Kostakis ID, Alexandrou A, Armeni E, Damaskos C, Kouraklis G, Diamantis T, Tsigris C. Comparison between minimally invasive and open gastrectomy for gastric Cancer in Europe: a systematic review and meta-analysis. Scan J Surg. 2017;106(1):3-20.

17. Quan Y, Huang A, Ye M, Xu M, Zhuang B, Zhang P, Yu B, Min Z. Comparison of laparoscopic versus open gastrectomy for advanced gastric cancer: an updated meta-analysis. Gastric Cancer. 2016;19(3):939-50.

18. Kitano S, Shiraishi N, Uyama I, Sugihara K, Tanigawa N, Japanese laparoscopic surgery study G. A multicenter study on oncologic outcome of laparoscopic gastrectomy for early cancer in Japan. Ann Surg. 2007;245(1):68-72.

19. Dutta S, Fullarton GM, Forshaw MJ, Horgan PG, McMillan DC. Persistent elevation of C-reactive protein following esophagogastric cancer resection 
as a predictor of postoperative surgical site infectious complications. World J Surg. 2011;35(5):1017-25.

20. Hoeboer SH, Groeneveld AB, Engels N, van Genderen M, Wijnhoven BP, van Bommel J. Rising C-reactive protein and procalcitonin levels precede early complications after esophagectomy. J Gastrointest Surg. 2015;19(4):613-24.

21. Warschkow R, Beutner U, Steffen T, Muller SA, Schmied BM, Guller U, Tarantino I. Safe and early discharge after colorectal surgery due to Creactive protein: a diagnostic meta-analysis of 1832 patients. Ann Surg 2012;256(2):245-50.

22. Jung IK, Kim MC, Kim KH, Kwak JY, Jung GJ, Kim HH. Cellular and peritoneal immune response after radical laparoscopy-assisted and open gastrectomy for gastric cancer. J Surg Oncol. 2008;98(1):54-9.

23. Straatman J, Cuesta MA, Tuynman JB, Veenhof A, Bemelman WA, van der Peet DL. C-reactive protein in predicting major postoperative complications are there differences in open and minimally invasive colorectal surgery? Substudy from a randomized clinical trial. Surg Endosc. 2018;32(6):2877-85.

24. Sakuramoto S, Yamashita K, Kikuchi S, Futawatari N, Katada N, Watanabe M, Okutomi T, Wang G, Bax L. Laparoscopy versus open distal gastrectomy by expert surgeons for early gastric cancer in Japanese patients: short-term clinical outcomes of a randomized clinical trial. Surg Endosc. 2013;27(5):1695-705.

25. Zhang K, Xi H, Wu X, Cui J, Bian S, Ma L, Li J, Wang N, Wei B, Chen L. Ability of serum $\mathrm{C}$-reactive protein concentrations to predict complications after laparoscopy-assisted gastrectomy: a prospective cohort study. Medicine. 2016;95(21):e3798.

26. Kushner I, Rzewnicki D, Samols D. What does minor elevation of C-reactive protein signify? Am J Med. 2006;119(2):166 e117-128.

27. Dan Z, YiNan D, ZengXi Y, XiChen W, JieBin P, LanNing Y. Thirty-day readmission after radical gastrectomy for gastric Cancer: a meta-analysis. J Surg Res. 2019;243:180-8.

28. Tanaka Y, Kanda M, Tanaka C, Kobayashi D, Mizuno A, Iwata N, Hayashi M, Niwa Y, Takami H, Yamada S, et al. Usefulness of preoperative estimated glomerular filtration rate to predict complications after curative gastrectomy in patients with clinical T2-4 gastric cancer. Gastric Cancer. 2017;20(4):736-43.

29. Tamura T, Sakurai K, Nambara M, Miki Y, Toyokawa T, Kubo N, Tanaka H, Muguruma K, Yashiro M, Ohira M. Adverse effects of preoperative sarcopenia on postoperative complications of patients with gastric Cancer. Anticancer Res. 2019:39(2):987-92

30. Zhou J, Hiki N, Mine S, Kumagai K, Ida S, Jiang X, Nunobe S, Ohashi M, Sano T, Yamaguchi T. Role of Prealbumin as a powerful and simple index for predicting postoperative complications after gastric Cancer surgery. Ann Surg Oncol. 2017;24(2):510-7.

31. Inaoka K, Kanda M, Uda H, Tanaka Y, Tanaka C, Kobayashi D, Takami H, Iwata N, Hayashi M, Niwa Y, et al. Clinical utility of the platelet-lymphocyte ratio as a predictor of postoperative complications after radical gastrectomy for clinical T2-4 gastric cancer. World J Gastroenterol. 2017;23(14):2519-26.

32. Takeuchi D, Koide N, Suzuki A, Ishizone S, Shimizu F, Tsuchiya T, Kumeda S, Miyagawa S. Postoperative complications in elderly patients with gastric cancer. J Surg Res. 2015;198(2):317-26.

\section{Publisher's Note}

Springer Nature remains neutral with regard to jurisdictional claims in published maps and institutional affiliations.

Ready to submit your research? Choose BMC and benefit from:

- fast, convenient online submission

- thorough peer review by experienced researchers in your field

- rapid publication on acceptance

- support for research data, including large and complex data types

- gold Open Access which fosters wider collaboration and increased citations

- maximum visibility for your research: over $100 \mathrm{M}$ website views per year

At BMC, research is always in progress.

Learn more biomedcentral.com/submissions 